\title{
Sedative and Hypnotic
}

National Cancer Institute

\section{Source}

National Cancer Institute. Sedative and Hypnotic. NCI Thesaurus. Code C29756.

Any agent that depresses the central nervous system (CNS) and is used to induce calm and sleep. 